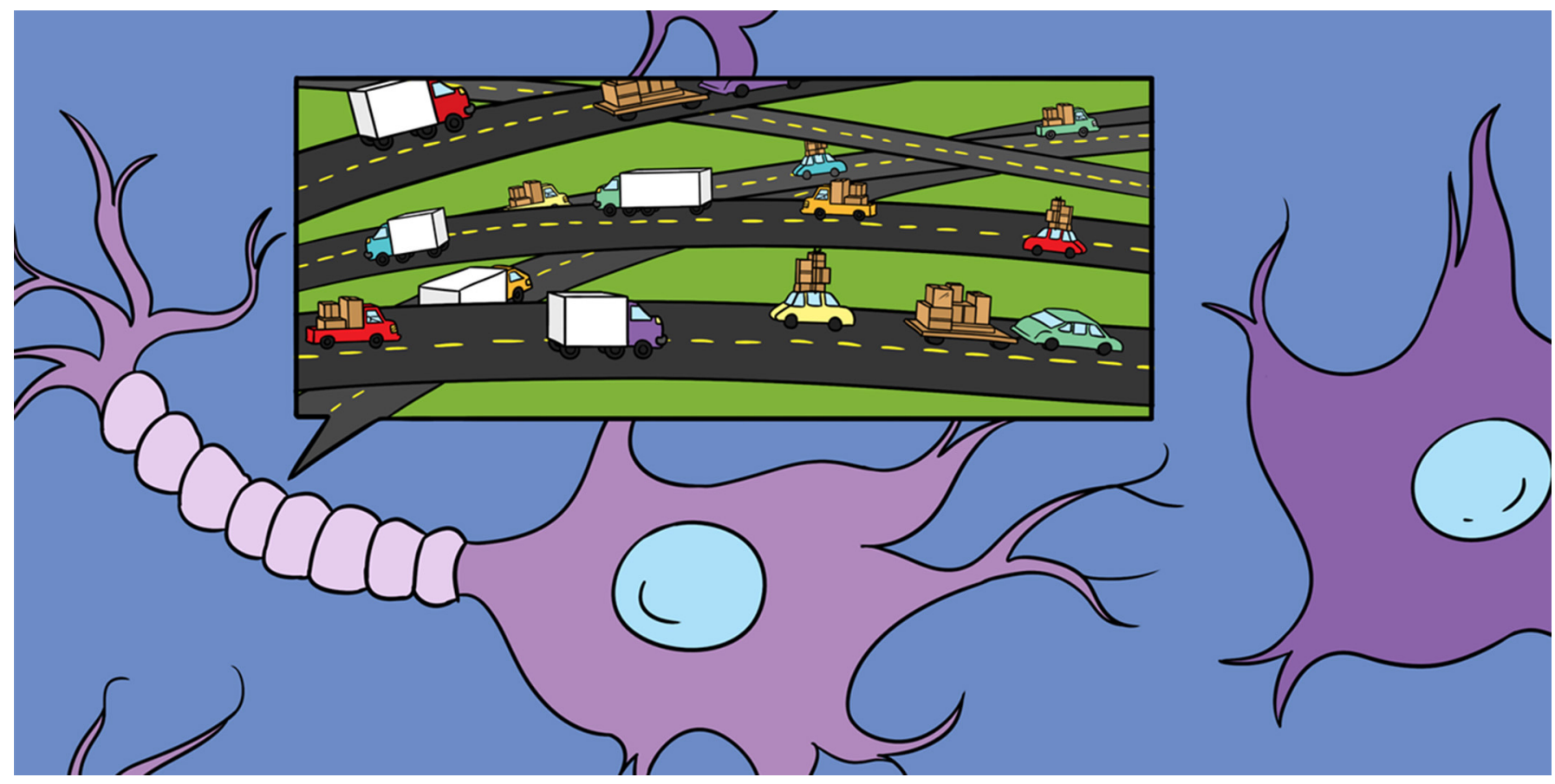

\title{
AXONAL TRANSPORT: THE DELIVERY SYSTEM KEEPING NERVE CELLS ALIVE
}

\section{James N. Sleigh ${ }^{1,2^{*}}$}

${ }^{1}$ Department of Neuromuscular Diseases, UCL Queen Square Institute of Neurology, London, United Kingdom

${ }^{2}$ UK Dementia Research Institute, University College London, London, United Kingdom

YOUNG REVIEWERS:

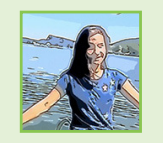

ISABELLA

AGE: 12

ALINE

AGE: 12
Cells are a little bit like cities, as they have all sorts of different cargoes that need to be constantly transported to particular destinations. This delivery process is especially important for nerve cells, because they have a long, thin tube-like structure called an axon. Nerve cells need to deliver a wide range of proteins and specialized structures up and down axons if they are to remain alive and healthy. Neurons do this using a delivery system called axonal transport. In this article, we will explore what axonal transport is and how it works. We will also discover what cargoes the nerve cells need to spread along their axons, and why this is so important for keeping nerves alive. Finally, we will look at what happens when axonal transport goes wrong and see how this may cause diseases of the nervous system.

\section{INTRODUCTION}

London is the buzzing capital city of the United Kingdom and it constantly bustles with millions of people going from one place to 
Figure 1

The transport networks in cities like London are similar to those found in cells. The image on the right shows a cell with its road-like microtubules stained green. Passengers, such as cellular structures called mitochondria (stained red) are transported along microtubules by cellular vehicles known as motor proteins. The nucleus, where the DNA is kept, is stained blue (see Footnote 1 for image credits) ${ }^{1}$

1 Photo credit: Denys Nevozhai (https://unsplash.com/ (adnevozhai) on Unsplash. Cell image credit: NIMR Francis Crick Institute, supplied by the Wellcome Collection (https://wellcome collection.org/works/v4 xfs8nv) licensed under CC-BY-NC 4.0 (https://creative commons.org/licenses/ by-nc/4.0/).

\section{MICROTUBULES}

Long, rod-like structures that act as roads along which motor proteins can drive axonal transport of cargoes.

\section{AXON}

A long, thin tube-like extension of a nerve cell that is vital for rapidly transferring signals over large distances.
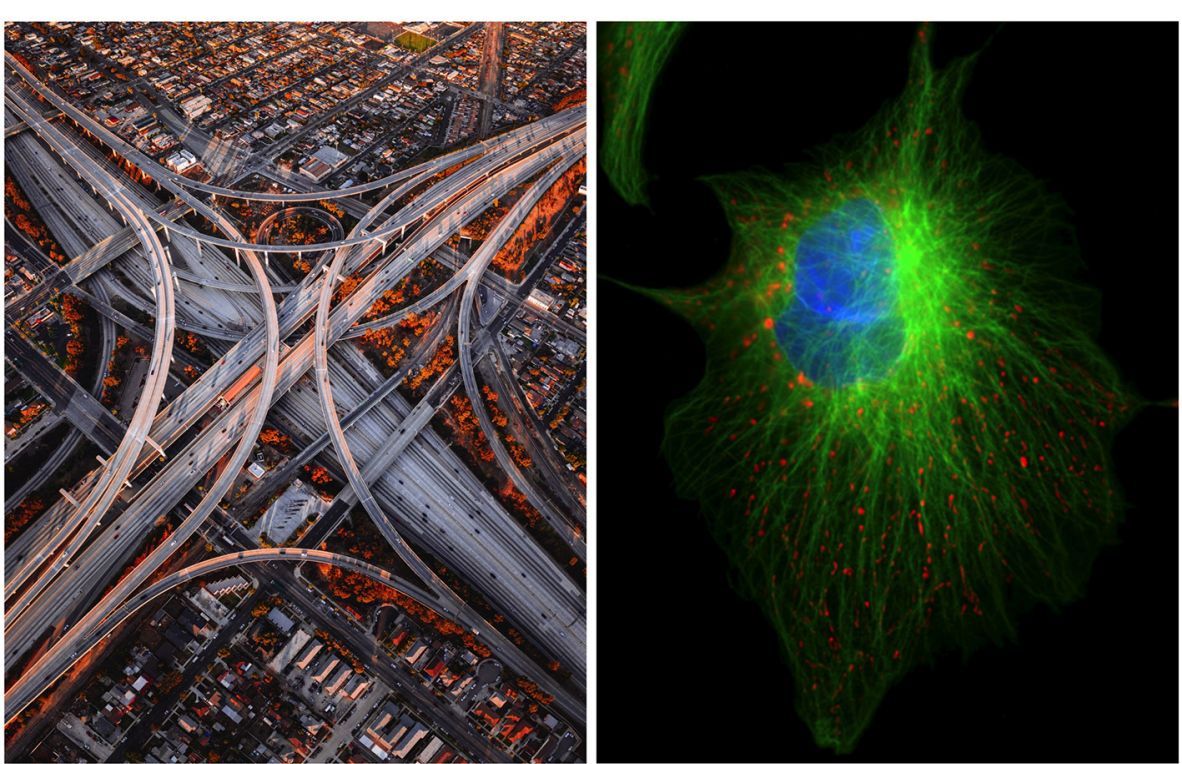

Figure 1

another. This movement requires a sophisticated and well-organized transport network, which includes almost 10,000 miles of roads.

Cells of the human body are similar to this hectic metropolis, because they must also efficiently and simultaneously transport many different substances to properly function and survive (Figure $1)$. The transport network in cells is made from structures called microtubules. Microtubules serve as the roads along which vehicles called motor proteins drive. Motor proteins transport a variety of passengers, including proteins and specialized structures, to where they are needed inside the cell.

Cells come in all sorts of specialized shapes and sizes depending on what they do. This is particularly true for nerve cells, which are the communicating cells found in the brain and spinal cord (Figure 2) [1]. Also known as neurons, nerve cells each have a long, tube-like extension called an axon that is vital for quickly transferring signals over large distances (Figure 2).

Peripheral nerves are found in the spinal cord and extend their axons outwards to connect with parts of the body, like the muscles. Axons of peripheral nerves can be over a meter long in adult humans and up to 10,000 times the length of the cell body, which is where the nucleus is and where most cellular materials are made (Figure 2). To give you an idea of this extreme shape, this axon is equivalent to London having a road that starts in the city center and then wraps around the equator more than 15 times!

As you may have guessed, given their length and shape, axons pose a major challenge for nerves, because some substances are needed 


\section{Figure 2}

Nerve cells, also known as neurons, are signaling cells found in the brain and spinal cord. Peripheral nerves are neurons found in the spinal cord that extend out thin, tube-like structures called axons to connect with tissues of the body, like muscles. Nerve cells can be divided into three basic compartments: (1) the cell body, which contains the nucleus and DNA; (2) the axon, which is a long, thin extension that can transmit signals; and (3) the axon tip or terminal, which contacts other cells.

\section{ANTEROGRADE}

\section{TRANSPORT}

Axonal transport from the cell body to axon terminal.

\section{RETROGRADE}

\section{TRANSPORT}

Axonal transport from the axon terminal to cell body.

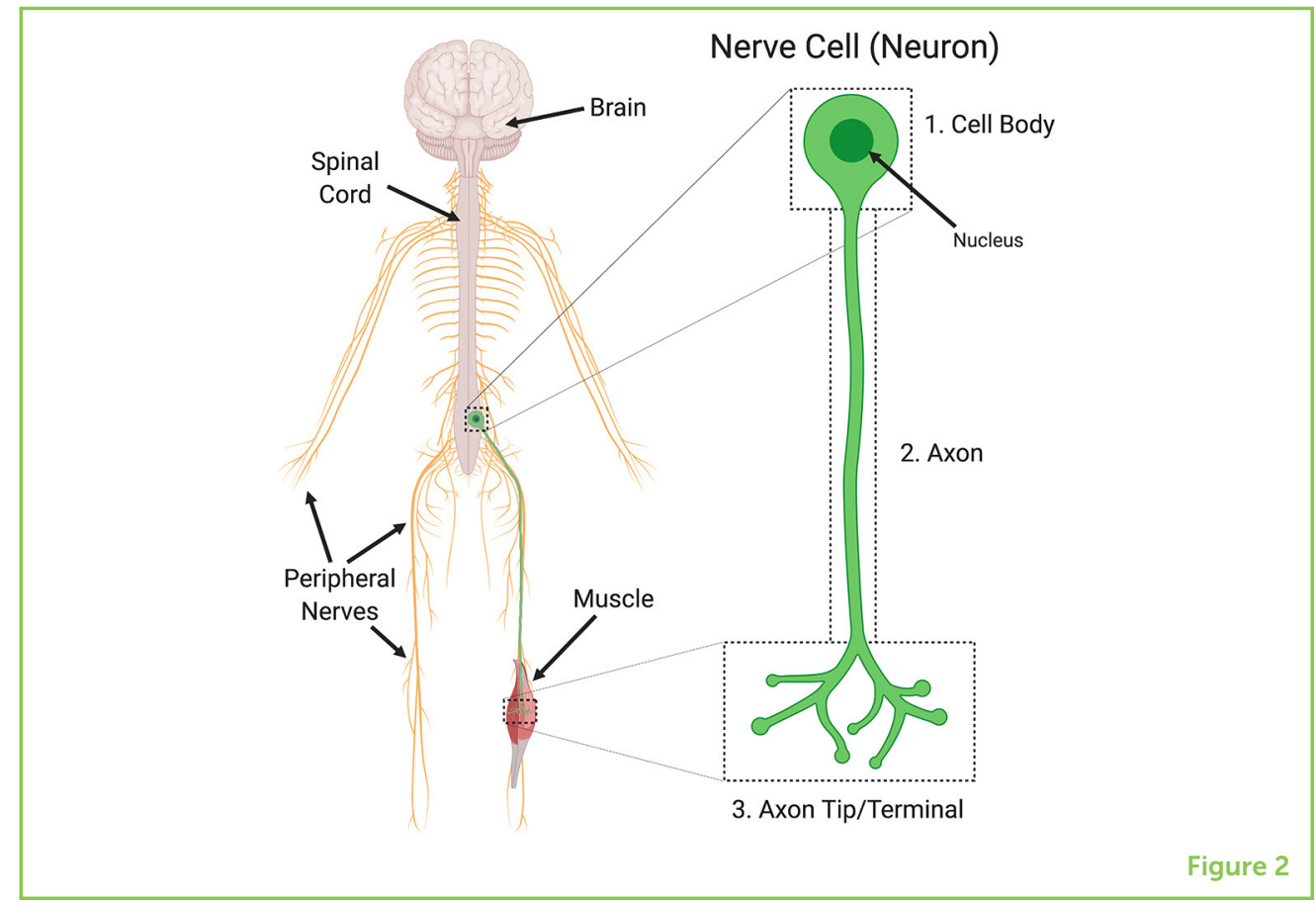

within the axon at particular points along its length, including all the way out to the tip. So how do nerve cells effectively deliver cargoes to where they are needed within the axon?

\section{AXONAL TRANSPORT: WHAT IS IT AND HOW DOES IT WORK?}

Axonal transport is the process by which nerve cells transfer substances between the cell body and axon tip. Axonal means anything relating to an axon.

Cargoes can be delivered in two directions. When substances are going toward the axon tip, it is known as anterograde transport, and when they are going toward the cell body, it is known as retrograde transport (Figure 3A). At any one time, thousands of cargoes can be delivered in both directions (Figure 3B).

Axonal transport is dependent on three key components:

1. Microtubules

2. Anterograde transport machinery

3. Retrograde transport machinery.

Microtubules are long, thin structures that provide the roads along which cargoes are transported in all cells. Every microtubule has one end that is stable and non-growing, called the minus-end, as well as an end capable of growth, called the plus-end. 
Figure 3

(A) Axonal transport can occur in two directions: anterograde transport is from the cell body toward the axon tip, and retrograde transport is from the axon tip back toward the cell body. (B) Many substances are simultaneously transported along microtubules found within axons. Motor proteins drive this transport by

connecting cargoes to the microtubules and using energy to move. Note that mitochondria, the energy-generating structures in the cell, can travel in both directions. (C) The motor protein kinesin moves toward microtubule plus-ends to direct anterograde transport of cargoes, such as mitochondria, toward the axon tip. Cytoplasmic dynein is the retrograde motor protein, which moves cargoes, such as autophagosomes, toward microtubule minus-ends and the cell body.

\section{KINESIN}

A motor protein that drives axonal transport of cargoes in the anterograde direction (toward the axonal terminal).

\section{CYTOPLASMIC} DYNEIN

A motor protein that drives axonal transport of cargoes in the retrograde direction (toward the cell body).

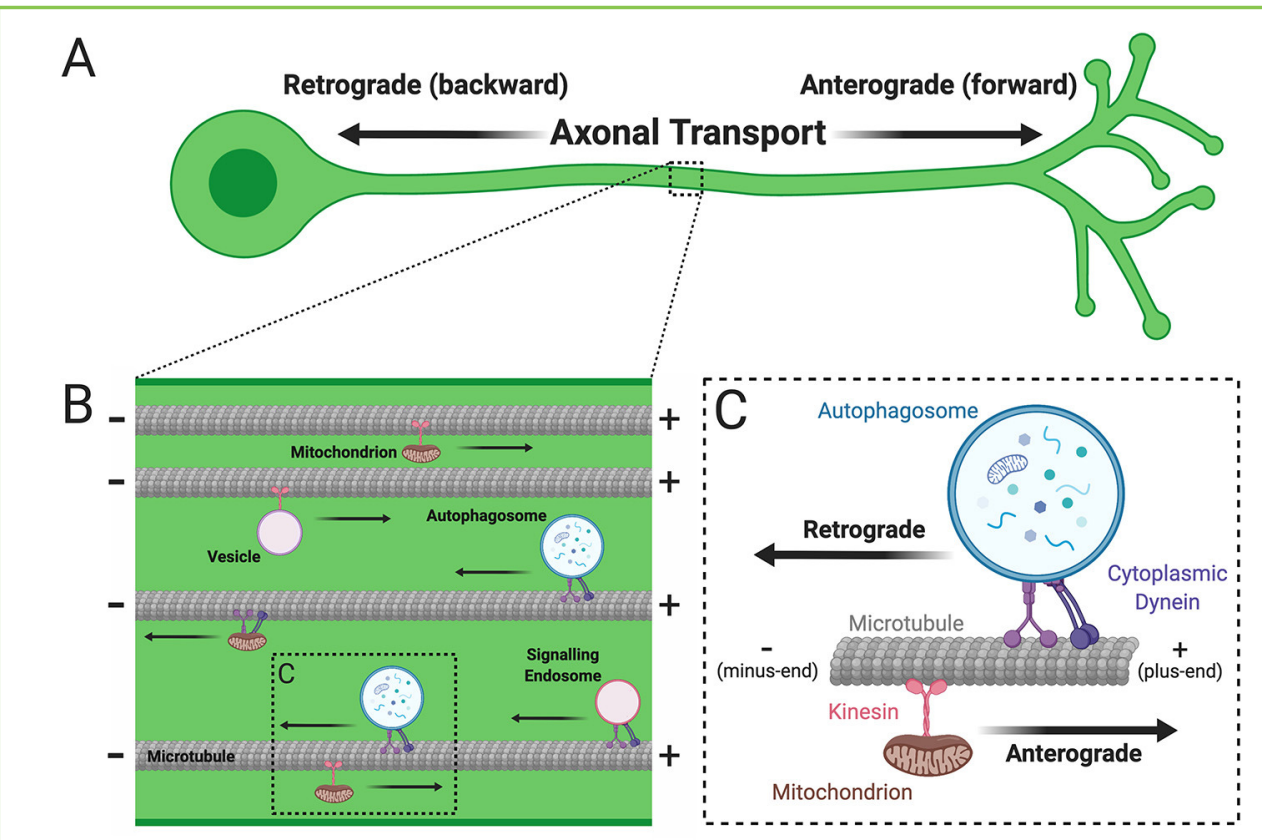

Figure 3

In the cell body, microtubules form networks that can have their minus-ends and plus-ends in any position, so materials can be transported in all directions. In addition, microtubules in the cell body are dynamic, which means that they can change their length and direction easily.

In contrast, microtubules within axons are more stable, as they must provide consistently maintained roads to permit efficient, long-range transport in either direction. Another feature specific to microtubules in axons is that their plus-ends all point toward the axon tip, and their minus-ends aim at the cell body (Figures 3B,C).

This uniform orientation is crucial for axonal transport, because the vehicles, known as motor proteins, that interact with cargoes and use energy to drive along microtubules, only travel in one direction. Anterograde transport toward the axon tip requires the motor protein kinesin, which drives toward microtubule plus-ends (Figure 3C). In the opposite direction, retrograde transport is dependent on the motor protein cytoplasmic dynein, which travels toward microtubule minus-ends and takes substances back toward the cell body.

\section{WHAT CARGOES ARE TRANSPORTED AND WHY IS THIS IMPORTANT?}

Motor proteins drive along microtubules to transport many passengers. Cargoes that are transported in the anterograde direction are generally different from those transported retrogradely. This is because the two processes serve distinct functions. However, some cargoes are 
SIGNALING

\section{ENDOSOME}

A specialized structure that travels retrogradely along axons to deliver survival signals to the cell body.

\section{AUTOPHAGOSOMES}

A specialized cell structure that travels retrogradely along axons to deliver damaged and unwanted substances to the cell body for degradation and recycling. transported in both directions, for example mitochondria, which produce energy for cells.

\section{Anterograde Cargoes}

Proteins come in thousands of forms with lots of diverse functions. Proteins are often needed at particular times and locations within nerves, both in the cell body and along the axon. To get to specific points in the axon, including down to the terminal, proteins must be transported from the cell body, where they are most often made, toward microtubule plus-ends (Figure 3). Particular proteins along the axon allow nerve cells to respond to the local environment. When these proteins are not successfully transported and are absent from the axon, the nerve cell is unable to function correctly, which can result in deterioration and nerve cell death.

Two additional cargoes transported toward the axon terminal are vesicles, which are like small sacks full of proteins or other substances, and mitochondria, which are the structures that provide a source of energy for the cell. If delivery of mitochondria is disrupted, for example in a disease or by a drug, the axon cannot produce the energy that it needs. This can harm nerve cell function, and in severe situations, lead to neuron death.

\section{Retrograde Cargoes}

Signaling endosomes are cellular structures that transport survival signals from axon terminals back to cell bodies (Figure 3B). When they arrive at the cell body, the signals from these endosomes help with nerve cell survival, for instance by increasing the production of proteins that help nerves to function and thrive. When this process is disturbed, nerve cells are more likely to die.

Autophagosomes (Figures 3B,C) are specialized structures that break down damaged and unwanted substances in the cell. Autophagosomes collect these waste substances from the axon and deliver them to the cell body, where the waste products can be efficiently removed or recycled. When autophagosome transport is impaired, potentially harmful substances can build up in the neurons.

Laboratory studies have shown that axonal transport is important to the development, function, and survival of all nerve cells. Because so many important cargoes are transported, problems with axonal transport are bad for nerve cells.

\section{WHAT HAPPENS WHEN AXONAL TRANSPORT GOES WRONG?}

Many laboratory experiments indicate that when axonal transport is not working properly, nerve cells are unhappy and can die. Also, 
research indicates that defects in axonal transport might play a role in most nervous system diseases, including Huntington's disease and multiple sclerosis, which are described in previous Frontiers for Young Minds articles [2, 3].

However, some of the most compelling evidence for what happens when axonal transport goes wrong and its importance for keeping nerve cells alive and healthy comes directly from humans.

The information needed to make microtubules and motor proteins is found in our DNA, in short, specific stretches called genes. Sometimes the information in genes can become damaged and result in something called a mutation (for more information on genes and mutations, see [4]). These mutations can cause a loss of the protein that a gene makes, or result in the production of a faulty form of the protein. Mutations in genes cause a range of diseases.

There is evidence that, when mutations occur in the genes that make the microtubules and motor proteins, this can cause human diseases that specifically affect the nervous system [5]. This suggests that when axonal transport is slowed or stopped due to these gene mutations, it affects the health of nerve cells and can lead to nervous system diseases. This is very much like what would happen if you were to block up the transport network in London and prevent people from getting to where they need to-it would be a disaster!

\section{CONCLUSION}

Many different cargoes are transported up and down axons of nerve cells in a process called axonal transport. This delivery system is important to the development, function, and survival of all nerve cells, and it often goes wrong in diseases that affect the nervous system.

\section{ACKNOWLEDGMENTS}

This work was supported by the Medical Research Council Career Development Award (MR/S006990/1) [JS]. The author would like to thank Dario Schiavo and Andrew P. Tosolini for critical comments on drafts of the manuscript. Figures 2 and 3 were generated using BioRender software (https://biorender.com/).

\section{REFERENCES}

1. Ahuja, C. S., Khazaei, M., Chan, P., O'Higgins, M., and Fehlings, M. G. 2018. Making neurons from human stem cells. Front. Young Minds 6:27. doi: 10.3389/frym.2018.00027 
2. Berman, T., and Bayati, A. 2018. What are neurodegenerative diseases and how do they affect the brain? Front. Young Minds 6:70. doi: 10.3389/frym.2018.00070

3. Caravagna, C. 2019. What is multiple sclerosis? Front. Young Minds 7:7. doi: 10.3389/frym.2019.00007

4. Rose, A. M. 2018. Junk DNA and cancer: why the trash in your cells is very important. Front. Young Minds 6:37. doi: 10.3389/frym.2018.00037

5. Sleigh, J. N., Rossor, A. M., Fellows, A. D., Tosolini, A. P., and Schiavo, G. 2019. Axonal transport and neurological disease. Nat. Rev. Neurol. 15:691-703. doi: 10.1038/s41582-019-0257-2

SUBMITTED: 05 July 2019; ACCEPTED: 28 January 2020;

PUBLISHED ONLINE: 18 February 2020.

EDITED BY: Shekher Mohan, College of Pharmacy, Natural and Health Sciences, Manchester University, United States

CITATION: Sleigh JN (2020) Axonal Transport: The Delivery System Keeping Nerve Cells Alive. Front. Young Minds 8:12. doi: 10.3389/frym.2020.00012

CONFLICT OF INTEREST: The author declares that the research was conducted in the absence of any commercial or financial relationships that could be construed as a potential conflict of interest.

COPYRIGHT () 2020 Sleigh. This is an open-access article distributed under the terms of the Creative Commons Attribution License (CC BY). The use, distribution or reproduction in other forums is permitted, provided the original author(s) and the copyright owner(s) are credited and that the original publication in this journal is cited, in accordance with accepted academic practice. No use, distribution or reproduction is permitted which does not comply with these terms.

\section{YOUNG REVIEWERS}
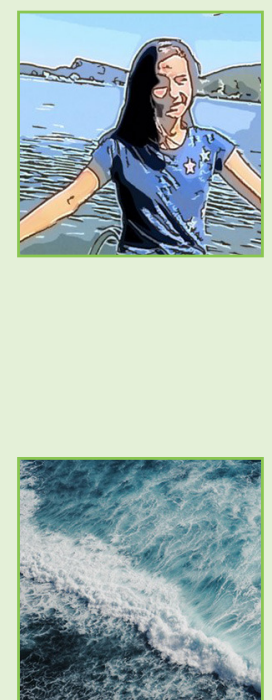

\section{ISABELLA, AGE: 12}

My name is Isabella and I am 12 years old. I was born in New York and I live in Switzerland. I love art, reading books, singing, dancing, and playing the piano. My favorite sport is swimming. I also have great interest in math, nature, and science, especially everything about space, time, and matter. In the future, I would like to be an aeronautic engineer or an architect. I am always very curious to learn more about the world around us.

\section{ALINE, AGE: 12}

My name is Aline, I am 12 years old. My favorite hobbies include theater, playing the clarinet, drawing, and reading. I am fascinated with Greek mythology; my favorite books include the Harry Potter and the Percy Jackson series. At school, I really enjoy Maths and Science. 


\section{AUTHOR}

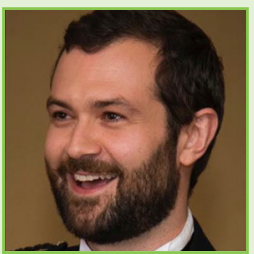

\section{JAMES N. SLEIGH}

I am a Senior Research Fellow at the Queen Square Institute of Neurology, University College London in the UK, and I run a small laboratory researching several nervous system diseases. Our main aim is to improve understanding of what goes wrong in these conditions in order to generate potential gene therapies that we can test in the laboratory. ${ }^{*}$ j.sleigh@ucl.ac.uk ${ }^{\dagger}$ orcid.org/0000-0002-3782-9045 